\title{
The effects of group blogging on the attitude towards virtual education in nursing students
}

\author{
Zohreh Sohrabi ${ }^{1}$, Hamid Reza Koohestani ${ }^{1 *}$, Nayereh Baghcheghi ${ }^{2}$, Somayeh Delavari ${ }^{1}$, \\ Zahra Rezaei Shahsavarloo ${ }^{2}$
}

Received: 16 Feb 2017

Published: 26 Dec 2017

\begin{abstract}
Background: Virtual education refers to a variety of teaching-learning methods that are implemented and supported electronically. The present study was conducted to determine the effects of group blogging on the attitude of nursing students towards virtual education.

Methods: This was a quasi-experimental pretest-posttest study in which all fifth-semester nursing students $(n=25)$ were selected and asked to design educational blogs on nursing of respiratory diseases. Attitudes of the participants towards virtual education were measured before and after the intervention.

Results: Pretest and posttest mean \pm SD were $2.98 \pm 1.03$ and $3.46 \pm 0.68$, respectively, showing a significant difference $(\mathrm{p}<0.05)$. There were significant differences before and after the intervention in the 2 subscales of importance of virtual education and interest in using virtual environment $(\mathrm{p}<0.05)$. On the other hand, there was no significant difference in the anxiety of using virtual environment before
\end{abstract} and after the intervention.

Conclusion: In general, the results revealed that blogging by nursing students could improve students' attitudes towards virtual education.

Keywords: Blogging, Students, Nursing, Attitude, Virtual, Education

Copyright $\odot$ Iran University of Medical Sciences

Cite this article as: Sohrabi Z, Koohestani HR, Baghcheghi N, Delavari S, Rezaei Shahsavarloo Z. The effects of group blogging on the attitude towards virtual education in nursing students. Med J Islam Repub Iran. 2017 (26 Dec);31:132. https://doi.org/10.14196/mjiri.31.132

\section{Introduction}

Virtual education refers to a range of teaching-learning methods that are implemented and supported electronically. The purpose of this type of education is to create knowledge pertinent to personal experience. Information and communication technology (ICT), whether networkbased or not, is the main medium to facilitate virtual education (1). Virtual education is rooted in the Western-style education, which is based on individualism and independent, self-directed, and active learning. Clearly, implementation of this type of learning depends on social and cultural conditions of the target society (2).

The key point of virtual education is that development of e-learning that neglects attitudes of the students is futile; in fact, it is imperative to learn about individuals' attitude about what is at stake. By learning about people's

Corresponding author: Hamid Reza Koohestani, koohestani.h@tak.iums.ac.ir

1. Department of Medical Education, School of Medicine, Center of Educational Research in Medical Sciences, Iran University of Medical Sciences, Tehran, Iran.

${ }^{2}$. School of Nursing and Midwifery, Saveh University of Medical Sciences, Saveh, Iran. attitudes, it is easier to predict and control their behaviors. In other words, success of a virtual learning attempt without considering the learners' attitude is not possible (3). The key actor in virtual education is the learner, and 4 key variables in this regard are attitude, experience, perception, and learning style; among them, the first one is the most effective (4). Weblog and blogging is one of the fields of virtual education (5); it is an opportunity provided by the internet that has grown in popularity in the recent years. Currently, thousands of weblogs are online in different fields and millions are attracted by them. The latest estimates indicate that one weblog is created every one second (6).

The first weblog was created by Dave Winer in 1994; however, the term "weblog" was first coined by John

$\uparrow$ What is "already known" in this topic:

Social, political, and artistic aspects of weblogs have been examined by different studies, while there is a paucity of studies on their scientific and academic functions.

$\rightarrow$ What this article adds:

Blogging by the nursing students could improve their attitudes towards virtual education. Blogs seem to be a feasible way to help students display their learning and experiences in different stages of their undergraduate nursing education. 
Barger in robot wisdom in 1997. The growth of the phenomenon was fueled when Pitas - the first free weblog service - was initiated in 1999. (7).

Actually, a weblog is an electronic journal to publish daily accounts about a specific issue by one or some people. The users are also allowed to comment about the content (8). As weblogs are still considered a young phenomenon, they have received a great deal of attention. The first Farsi weblog service was initiated in 2001; another service "www.blogfa.com" was launched in 2004, enjoying a great growth rate with more than a million users. In 2002, Farsi weblogs were fourth in the global ranking (5).

One of the factors affecting the popularity of weblogs is their unique features. Ease of initiating and running a weblog with no need to any special software or a special skill adds to the popularity of the services (9). Another effective element on the fast growth of weblogs is their availability (5).

Social, political, and artistic aspects of weblogs have been examined by different studies, while there is a paucity of studies on their scientific and academic functions. As shown, students do not find enough time to reflect in crowded and noisy classrooms so that the major portion of thinking function takes place outside the classroom (10). Results of a study revealed that students tend to have positive attitudes towards using the internet for learning purposes (11). Some research works have highlighted advantages of using weblogs for education like Faar (2011), who argued that using weblogs by nurses improved their communicational skills (12). Another study found that nursing students tended to have positive attitudes towards using weblogs to represent their learning in training courses (13).

Attitudes of the targets of virtual education programs highly affect the success or failure of the programs, and attitudes are reliable elements to predict the behavior of individuals (3). Virtual education is an online education course based on the internet. It is a Western education technology based on values such as individualism, independent learning, autonomy, and active participation of the learner. Popularity of this type of learning is growing thanks to advantages such as cost saving, reusability, and flexibility $(2,14)$.

Borhani et al. showed that participating in a virtual education course improved attitudes of the participants about the course. The participants received educational material from the Website of Kerman University of Medical Sciences. They had 8 weeks to study the material (video and audio files (Flash files)) that had been uploaded into the website (15).

The authors found no published article on surveying the effect of group blogging on attitudes of nursing students about virtual education.

Given the unique role of virtual education in medical sciences, (Blogging is a tool for virtual education) and paucity of studies and documents in this regard, the authors conducted a study to examine the effects of group blogging for a 1.2 credit course of respiratory disease nursing on attitudes of the students about virtual education. The present study attempted to find whether group blogging on the course material affect the attitude of the students about virtual education.

\section{Methods}

A quasi-experimental pretest-posttest study in which all fifth-semester nursing students $(n=25)$ in Saveh University participated was conducted in 2015. Inclusion criteria included all the fifth-semester undergraduate nursing students who have selected the course for respiratory diseases, and those students who were willing to participate in study. Failure to precisely fill out the questionnaire was considered as the exclusion criteria. In this research, sampling was not done and all available and eligible students were selected (census).

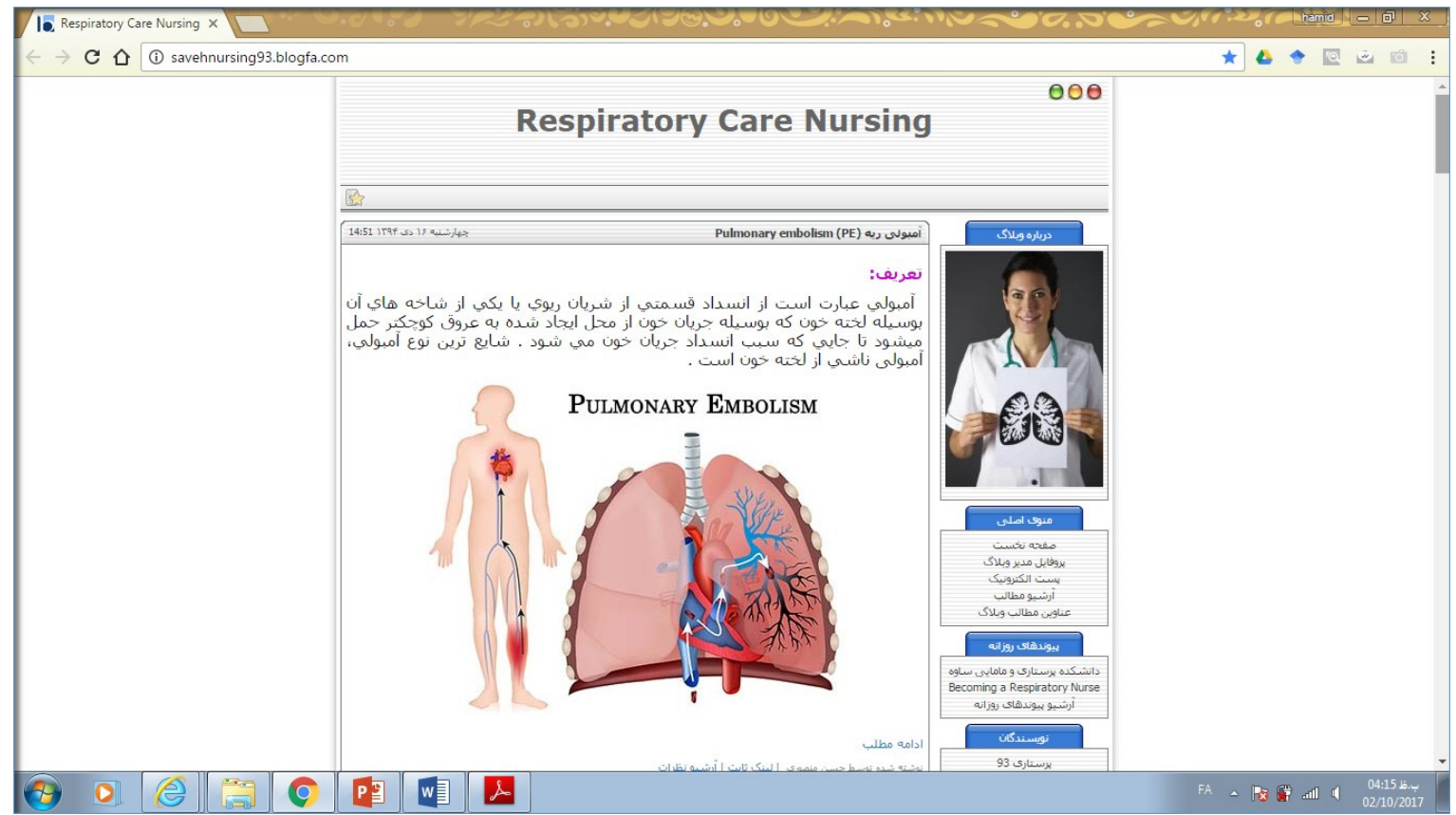

Fig. 1. Example the weblog page 


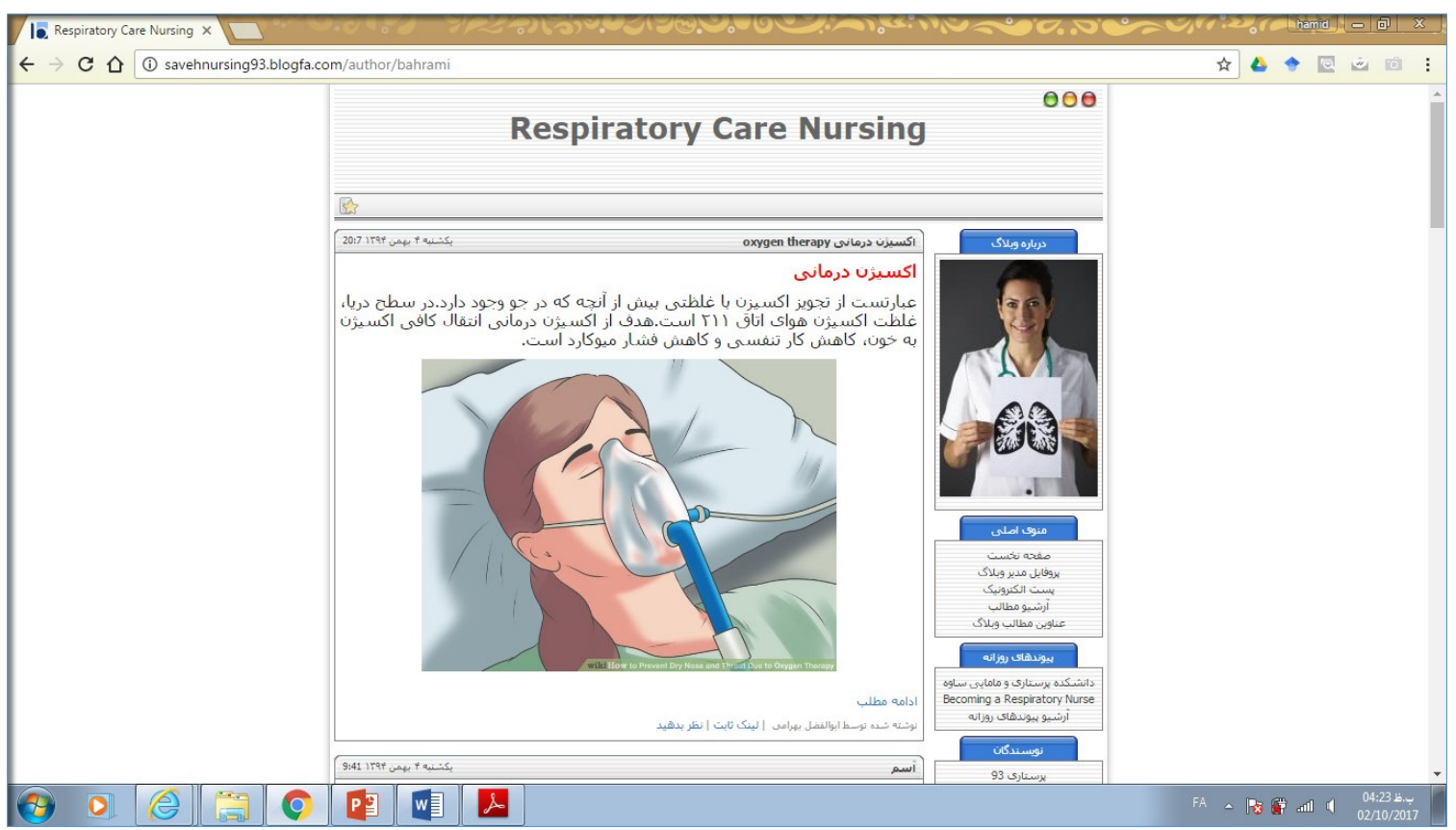

Fig. 2. Example of the weblog page

The students were asked to design an educational web$\log$ for respiratory disease nursing. Before initiation of the intervention, the participants' attitudes about virtual education was measured using Attitude Towards Virtual Education Questionnaire, and then, they developed a weblog as a group work and based on task assignments. The content included topics determined by the lecturer, and the participants were allowed to mention their name in the weblog as well. For instance, after discussing the topic asthma in the class, some of the students would prepare the content (pictorial if possible) and post it on the weblog and mention their name at the end. Then, the lecturer and other students could send feedbacks, and the final work of each group would be evaluated based on the feedbacks. This process was followed until the end of semester, and then, the participants were asked to fill out the questionnaire once again (Figs 1,2) (blog address: http://saveh nursing93.blogfa.com).

The students' attitude towards virtual education was examined using 20 questions with 3 subscales of importance of virtual education (9 questions), joy of working in virtual environment ( 7 questions), and anxiety about working in virtual environment (4 questions). The statements were scored based on a 5 -point scale ( $1=$ completely disagree, $5=$ completely agree). This questionnaire was designed and validated by Borhani et al. Content validity of the questionnaire was checked by providing the tool to 10 faculty board members. Internal consistency method was used to determine the reliability of the questionnaire, and
Cronbach's alpha was found to be equal to 0.85 (15). Content validity was used to determine the validity of the questionnaire, and the reliability of the questionnaire was examined through split half and Cronbach's alpha. The collected data were analyzed in SPSS using descriptive statistics (mean and standard deviation) and paired $t$ test. With respect to adherence to ethical concerns, the study plan was submitted to ethics committee of the university to obtain approval, and permission was secured from officials of the Faculty of Nursing and Midwifery. Prior arrangements were made with the head of the Department of Nursing, and the participant signed a letter of consent.

\section{Results}

All the questionnaires were returned completely filled out (response rate $=100 \%$ ). Out of 25 participants, 15 were females $(61.9 \%)$ and 10 male $(38.1 \%)$. The participants' age ranged from 19 to $23(20.4 \pm 0.69)$ years. All the students were local residents of city of Saveh, and 6 of them were married. A total of 20 students had access to the internet at home or the dormitory and the majority of the participants used a computer for 4 to 10 hours weekly on average. The students used the computer for educational purposes for 1 to 3 hours per week.

Pretest and posttest mean \pm SD of attitude towards virtual education of the students were $2.98 \pm 1.03$ and $3.74 \pm 0.68$, respectively, indicating a significant difference $(\mathrm{p}<0.05)$ between before and after the intervention.

Table 1 compares the means of attitude scores before

Table 1. The mean and standard deviation of attitudes towards virtual education before and after the intervention

\begin{tabular}{|c|c|c|c|c|c|c|}
\hline \multirow[t]{2}{*}{ Subscale of virtual education } & \multicolumn{2}{|c|}{ Pretest } & \multicolumn{2}{|c|}{ Posttest } & \multirow[t]{2}{*}{$\mathrm{t}$} & \multirow[t]{2}{*}{$\mathrm{p}^{*}$} \\
\hline & Mean & SD & Mean & SD & & \\
\hline Importance of virtual education & 2.84 & 0.96 & 3.64 & 0.79 & 4.67 & 0.002 \\
\hline The joy of working in virtual environment & 2.8 & 0.99 & 3.84 & 062 & 4.43 & $<0.001$ \\
\hline Anxiety of working with virtual tools & 2.96 & 1.13 & 2.9 & 0.64 & 0.75 & 0.89 \\
\hline Total & 2.86 & 1.03 & 3.46 & 0.65 & 6.76 & $<0.001$ \\
\hline
\end{tabular}


and after the intervention based on the subscales. As listed, there was a significant difference between pretest and posttest scores of the 2 subscales of importance of virtual education and interest in working in virtual environment $(\mathrm{p}<0.05)$. However, no significant difference was found between pretest and posttest scores of anxiety of working in virtual environment $(\mathrm{p}>0.05)$.

In general, the results showed that group blogging by the student had positive effects on attitudes of the students in the 3 subscales of importance of virtual education, joy of working in virtual environment, and anxiety of working with virtual systems.

\section{Discussion}

Rapid growth of the institutions providing e-learning and qualitative and quantitative growth of the fields of studies available electronically highlight the need for examining the services and employing the results for programming and planning. Expansion of virtual education in medical sciences is part of the 12 packs of innovation and revolution of medical sciences education, which is followed by medical sciences universities in Iran.

As noted, the main issue in the acceptability of virtual education is the learners' attitudes toward virtual education. In the present study the effect of group blogging on the attitudes of nursing students about virtual education was examined. The findings showed that attitudes towards virtual education was not promising before the intervention and the obtained scores were below 3 in the 3 subscales of importance of virtual education, joy of working in virtual environment, and anxiety of working with virtual systems. Lack of experience in virtual education may lead to fear of experiencing something new and may be a reason for low scores obtained by the participants before the intervention.

Still, the situation changed significantly after group blogging intervention and the participants developed more positive attitudes towards virtual education.

Attitudes are acquirable and learned. Nature has insignificant role in shaping attitudes (18). Psychologists believe that one way to improve attitudes is to experience the subject or object directly. A positive attitude about an object might be the outcome of a direct and pleasant experience with the object, while negative attitude might be rooted in a bitter experience (19). The information acquired through personal experiences or information from other sources can affect one's attitudes so that people's attitudes change as they experience different things (20). In the present study, direct experience with group blogging and using it for education purposes had positive effects on the participants' attitudes towards virtual education.

Databanks search yielded no article with identical subject; however, relatively similar papers were found and some are discussed here. Studies have confirmed higher rates of acceptability of blogging for educational purposes among students. Lin and Shen (2013) examined attitudes of nursing students towards using weblogs in the clinical training courses and reported that attitudes were positive in general. Most of the students believed that blogging was an opportunity to seek motivation and emotional support of the classmates throughout the training course. They also stated that reading contents of their friends' blogs affected the development of their professional knowledge. Moreover, all the students stated that reading their classmates' content was also useful to find out about others' attitudes (9).

Borhani et al. surveyed the effects of virtual education on attitudes of nursing students about virtual education. They showed that attending a virtual course improved attitudes of the participants (15). However, there are methodological differences, as their participants took part in the course via virtual education system of the university, while in our study, the participants were guided by their professors and the students were in charge of creating, designing, and developing contents of the weblogs.

Namvar et al. surveyed the effects of blogging learning based on problems solving approach on development of rational thinking of the English Language students in Azad Islamic University-Ardabil Branch. They found that the intervention had positive effects on the growth of rational thinking in the participants (5).

Farjah (2009) studied using weblogs in a French class and reported that the participants found weblogs a reliable tool for learning a second language (10).

In short, the results showed that group blogging by students improved their attitudes towards virtual education. Teachers may use weblogs as a tool to design learning activities and combine the curriculum with ICT. Given that most students were interested in blogging, they can be motivated to write essays and publish them through weblogs or take part in blogging competition and express their ideas and creativities. Moreover, blogging activities and similar group tasks can be reflected in the final score of the students.

Our findings indicated that blogs are a potentially useful tool for nursing students to share their knowledge and scientific information to improve virtual learning attitude. Educational benefits of blogging may even increase if trained nurse educators help facilitate significant and purposeful discussions, which emerge from blog entries, and comment on students' learning issues with the chance to reach a large society of learners.

Nursing students and other students can use blogs to share a large range of experiences and learning aspects during school as well as individual social experiences in the outside environment of the university.

\section{Conclusion}

In general, the results indicated that blogging by the nursing students could improve students' attitudes towards virtual education. Blogs seem to be a feasible way to help students display their learning and experiences in different stages of their undergraduate nursing education and share them with a geographically independent society.

\section{Limitations and suggestions for future research}

The small sample size of this study was limited to students from one school of nursing, and thus the results cannot be generalized. It is recommended that this study be 
replicated with a larger sample size and on other medical students. However, this was a pilot study and the results provided direction to nursing teachers and nursing education program planners.

\section{Conflict of Interests}

The authors declare that they have no competing interests.

\section{References}

1. Tavangarian D, Leypold ME, Nölting K, Röser M, Voigt D. Is elearning the solution for individual learning. EJEL. 2004;2(2):273-80.

2. Kian M. Challenges of virtual education: a report of what are not learned. MEDIA. 2014;5(3):11-21.

3. Teo T, Noyes J. Development and validation of a computer attitude measure for young students. Comput Human Behav. 2008;24(6):2659-67.

4. Dorrian J, Wache D. Introduction of an online approach to flexible learning for on-campus and distance education students: lessons learned and ways forward. Nurse Educ Today. 2009;29(2):157-67.

5. Sarafzadeh M. Some educational and research applications of Blogs. NAMA J. 2005;5(1):1-4. (Persian)

6. Williams JBJ, Joanne. Exploring the use of blogs as learning spaces in the higher education sector. Australas. J Educ Technol. 2004;20(2):232-47

7. Esmaeil S. Copyright in weblogs. Quart J Knowl Studies. 2009;1(3):87-99. (persian)

8. Asnafi A. Blogs, new bringing Internet for Libraries. Book journal. 2005;16(2):167-72.(Persian)

9. Namvar Y, Naderi E, Shariatmadari A, Seyf naraghi M. The Impact of Web-based learning with a problem-solving approach on reflective thinking development in english language students of Islamic Azad University of Ardabil. Research in curriculum planning 2011;8(28):84-95. (Persian)

10. Lenhart A, Simon M, Graziano M. The Internet and education: findings of the Pew Internet \& American Life Project. 2001.

11. Oral B. The evaluation of the student teachers' attitudes toward Internet and democracy. Comput Educ. 2008;50(1):437-45.

12. Farr T. Using a blog to improve communication. Nurs Manag. 2011;42(6):52-3.

13. Lin KY, Shen YF. The nursing students' attitude toward using blogs in a nursing clinical practicum in Taiwan: A 3-R framework. Nurse Educ Today. 2013;33(9):1079-82.

14. Sanayei A. Electronic commerce: a managerial perspective. Tehran: Dibagaran Institute; 2011. p.11-47. (Persian)

15. Borhani F, Vatanparast M, Abbaszadeh A, Seyfadini R. The Effect of training in virtual environment on nursing students attitudes toward virtual learning and its relationship with learning style. IJME. 2012;12(7):508-17

16. Azarbayejani M. Social psychology. tehran: SAMT publication; 2003. p. 45-79. (Persian)

17. Golipour A. Organizational Behavior Management. tehran: SAMT publication; 2007. p. 25-39. (Persian)

18. Esmaeili R. Attitudes and characteristics of its components. Teachings quarterly. 2004;21:5-8. (Persian)

19. Koohestani HR, Baghcheghi N. The effects of team-based learning techniques on nursing students' perception of the psycho-social climate of the classroom. Med J Islam Repub Iran. 2016;30:437.

20. Karimi Y. Attitude and attitude change. Tehran: Virayesh Publication. 2015.p.19-38. (Persian) 